\title{
Urban Noise Pollution Assessment and its Non-Auditory Health Effects on the Residents of Chiniot and Jhang, Punjab, Pakistan
}

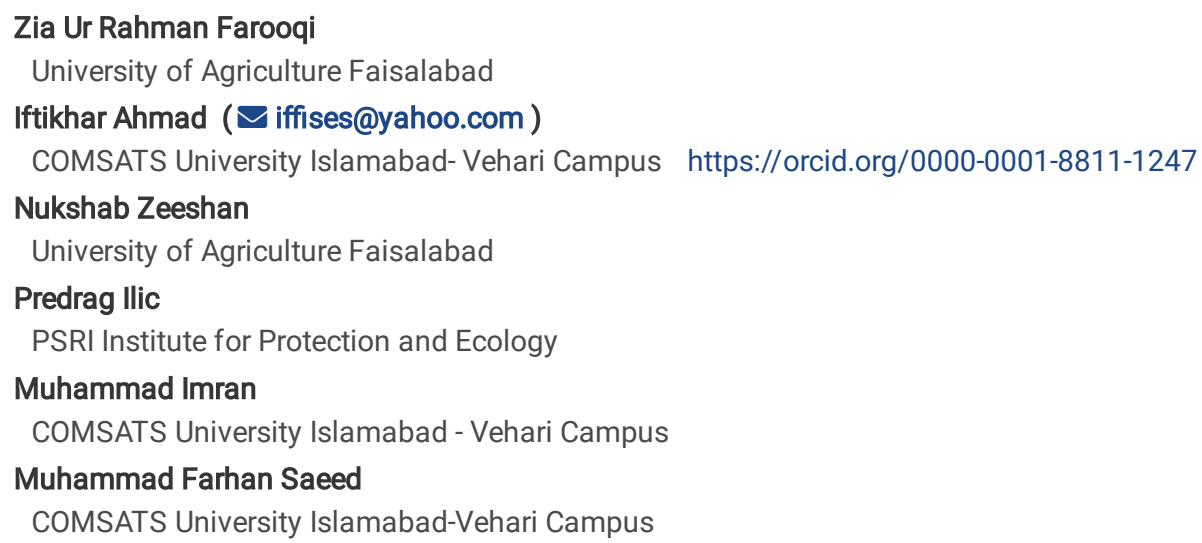

Keywords: Health outcomes, Noise, Regression analysis, Traffic density, Urban environment

Posted Date: February 16th, 2021

DOI: https://doi.org/10.21203/rs.3.rs-167876/v1

License: (c) (i) This work is licensed under a Creative Commons Attribution 4.0 International License. Read Full License 


\section{Abstract}

Noise pollution is an emerging global problem therefore, it is imperative to determine noise level especially in the urban environment and its implications on human health. The objectives of this study were i) to assess the urban noise pollution and traffic density of Chiniot and Jhang and ii) to determine non-auditory health effects of noise pollution on the residents of both cities. Noise pollution was examined from 181 locations (103 from Jhang and 78 from Chiniot) and categorized into hospitals, educational, religious and recreational, residential, industrial areas, and traffic intersections. Noise levels measurements were taken using integrated sound level meter. The urban noise data showed $82 \%$ of the sites in Jhang and $95 \%$ in Chiniot exceeded the noise limits set by NEQS-Pak and WHO. Moreover, higher intensity of noise pollution ( $\geq 100 \mathrm{~dB}$ ) was recorded in Chiniot (17 sites) than in Jhang ( 1 site). Regression analysis showed relatively strong relationship of traffic density with noise at Chiniot $\left(R^{2}=0.48\right)$ compared to Jhang $\left(R^{2}=0.31\right)$. However, spatial variability of noise with traffic density was observed at both cities. Survey study revealed that all the respondents in Jhang and Chiniot suffered from many noise related health problems such as annoyance (53 and $51 \%$ ), depression (45 and $47 \%$ ), dizziness (61 and 65\%), headache (67 and 64\%), hypertension (71 and 56\%), hearing loss (53 and 56\%), physiological stress (65 and $65 \%$ ), sleeplessness (81 and $84 \%$ ), and tinnitus (70 and 62\%) due to noise, respectively. It is concluded that noise pollution is higher in Chiniot due to high traffic density resulted from higher population density and cottage industry. It is recommended that vehicles maintenance, family and urban planning could be effective measures to reduce urban noise pollution.

\section{Introduction}

The urban noise pollution is recognized as a major problem for the quality of life in metropolitan cities all over the world (Ozer et al. 2009; Fredianelli et al. 2019). As an important environmental element with social and aesthetic attributes, the quality of soundscape is one of the most important factors for environmental perception (Brown and Muhar 2004; Kang 2006; Yong et al. 2011; Zhang et al. 2017). Noise is mainly produced from industrial processes, traffic vehicles, railway, air traffic, construction and domestic noise (Braat-Eggen et al. 2017; Fedorko et al. 2018; Hahad et al. 2018). Noise pollution is primarily increased due to increase in the number of vehicles on roads, however, there are many factors manipulating the level of traffic noise such as car type and their condition, quality of roads, vehicles density and their physical state, and weather conditions etc. (Wolniewicz and Zagubień 2015). The buildings with low sound insulation have higher level of environmental noise (Ng and Hui 2008; Paiva et al. 2019). It is annoying and disturbing people in their daily life activity (Auger et al. 2018; Javaherian et al. 2018; Mahmud et al. 2019; Farooqi et al. 2020). Normal people can bear the noise up to $80 \mathrm{~dB}$ and it may damage the nerves directly if it exceeds that limitation (Purwaningsih et al. 2018). It is thought that the excessive noise levels in the urban environment is due to the industries (Bamane et al. 2019; Zeydabadi et al. 2019), community noise (Picaut et al. 2019; Bridger et al. 2019; Wilson 2019), and traffic on the roads (Cramer et al. 2019; Jørgensen et al. 2019; Paiva et al. 2019; Cai et al. 2019). It was observed from the previous studies that many sites in Faisalabad, Pakistan have SPLeq $>100 \mathrm{~dB}$, which were exceeding the permissible limits of Pakistan Environmental Protection Agency (Farooqi et al. 2017). Urban noise is not only the issue in Pakistan, but also in most parts of the world. In seven major cities of India, majority of sites ranged noise level between 75-90 dB in commercial areas while the limits were 65 $\mathrm{dB}, 67-93 \mathrm{~dB}$ in industrial zone against the limit of $75 \mathrm{~dB}, 75-85 \mathrm{~dB}$ was recorded in residential area against $55 \mathrm{~dB}$, and $60-90 \mathrm{~dB}$ range was recorded in silent zones against the limits of $50 \mathrm{~dB}$ (Garg et al. 2016). Same patterns of urban noise pollution were reported in London (Tonne et al. 2018), and up to $110 \mathrm{~dB}$ noise levels were recorded in subways in Hong Kong which were exceeding the permissible levels of $70 \mathrm{~dB}$ set by WHO (Xu et al. 2019). It is also reported that urban noise significantly affect the property prices by $24.4 \%$ (Zheng et al. 2020). The main causes of urban noise are the industries and their processes (Liu et al. 2019; Farooqi et al. 2020), and increasing traffic density in the cities due to population increase growth. Traffic vehicles use horns openly which cause noise more than the industrial processes does (Fecht et al. 2016). Increased noise levels due to traffic causes different human health interventions like hypertension (Hahad et al. 2019; Nassiri et al. 2019), headache (migraine) (Ishikawa et al. 2019), tinnitus (Shore and Wu 2019; Wang et al. 2019; Hashim et al. 2019), hearing loss (Kujawa and Liberman 2019; Defourny et al. 2019), sleep disturbances (Brink et al. 2019; Farooqi et al. 2020). According to a report by WHO, 45,000 DALYs (disability-adjusted life year) are lost in European citizens because of noise-induced health effects, 903,000 DALYs because of noise-induced sleep disturbance, 61,000 DALYs because of noiseinduced cardiovascular disease, and 22,000 DALYs because of tinnitus (Münzel and Sørensen 2017).

In Pakistan, the urban noise is affecting the citizens health with the same pace, but the noise levels and their effects are not studied in most cities in the country. Therefore, the present study was conducted i) to assess the urban noise pollution and traffic density of Chiniot (new civilization) and Jhang (old civilization), ii) survey-based assessment of non-auditory health effects of noise on the residents of both cities and iii) production of baseline data in the form of geographic maps through modern software technologies (ArcGIS and XLSTAT) for Government considerations and public awareness. This study could also help Govt. agencies in decision making for management of noise pollution and its health impacts on residents of targeted cities.

\section{Materials And Methods}

\subsection{Geo and Demo-graphic features of study area}

Jhang and Chiniot are the developing cities of Punjab, Pakistan. Chiniot was a tehsil of District Jhang but now it is independent District of Punjab. The Chiniot is densely populated ( 524.9 persons $/ \mathrm{km}^{2}$ ) as compared to Jhang ( 431.9 persons $\left./ \mathrm{km}^{2}\right)$. According to recent census in 2017 , Jhang has 2.74 and Chiniot has 1.36 million populations with the increasing rate of 2.04 and $1.36 \%$, respectively (Table 1 ). Consequently, urban noise is 
increasing day by day. Traffic density is the main factor which contributes to increasing urban noise. More than 63\% (Jhang) and 68\% (Chiniot) of passenger's travel within these cities using motorbikes, cars, and buses, which are the significant factors to produce noise and influence inhabitants. This study compiles the basic data about urban noise pollution, traffic density and its impact on residents of both cities. Figure 1 describes all the sampling locations for urban noise pollution determination of Jhang (green) and Chiniot (yellow) cities.

Table 1

Geo- and Demo-graphic features of Chiniot and Jhang during the study period

\begin{tabular}{|llll|}
\hline Information & Unit & \multicolumn{3}{l|}{ Information of } \\
\cline { 2 - 4 } & & Chiniot & Jhang \\
\hline Population (2017 Census) & Millions & 1.37 & 2.743 \\
\hline Population Growth Rate & $\%$ & 1.86 & 2.04 \\
\hline Rank according to population in Pak. & - & 28 & 18 \\
\hline Geographical area & $\mathrm{km}^{2}$ & 26,10 & 63,53 \\
\hline Population density & $\mathrm{No}$ of persons $\mathrm{km}^{-2}$ & 524.9 & 431.9 \\
\hline Latitude & - & $31^{\circ} 43^{\prime} 10^{\prime \prime} \mathrm{N}$ & $31^{\circ} 16^{\prime} 10^{\prime \prime} \mathrm{N}$ \\
\hline Longitude & - & $72^{\circ} 59^{\prime} 3^{\prime \prime} \mathrm{E}$ & $72^{\circ} 18^{\prime} 58^{\prime \prime} \mathrm{E}$ \\
\hline Height from sea level & $\mathrm{M}$ & 179 & 158 \\
\hline Annual Rainfall & $\mathrm{Mm}$ & 336 & 679 \\
\hline Avg. temperature during winter & ${ }^{\circ} \mathrm{C}$ & $9 \pm 4$ & $11 \pm 4$ \\
\hline Humidity & $\%$ & $68.8 \pm 4$ & $65.3 \pm 4$ \\
\hline Wind speed & $\mathrm{km} \mathrm{h}$ & $7.3 \pm 1.9$ & $6.8 \pm 1.9$ \\
\hline
\end{tabular}

\subsection{Measurement of noise levels}

Field measurements were taken during September 2019 by sound level meter (SLM) for obtaining data about noise level ( $\mathrm{L}_{\text {aeq}}$ ) and traffic densities $\left(T_{f}\right)$ in Jhang (103 locations comprised of traffic intersections (34), commercial places (6), educational institutes (18), hospitals (10), residential areas (18), religious and recreational areas (9), and industrial areas (8) and Chiniot (78 locations comprised of traffic intersections (17), commercial places (13), educational institutes (12), hospitals (10), residential areas (10), religious and recreational areas (10), and industrial areas (7) (Fig. 1). The measurement and evaluation of noise levels were performed in compliance with the national legislation of Pak-EPA (lyer et al. 2017). Noise levels were measured by placing SLM at tripod at the level of 1.7 meters from the level of the pavement, distance of 3 meters from the noise reflecting surface. The intensity of noise was measured in afternoon one by one at selected areas for 15 min per reading per location (near the receivers) by using SLM. The sound level was measured as A-weighting using SLM model TES-1351B type 2 with a frequency range of 20-8000 Hz and accuracy of $\pm 1.0 \mathrm{~dB}$ (94 dB @1 kHz). The SLM was calibrated by the internal oscillator at the rate of $1 \mathrm{kHz}$ sine wave general (94 dB) (Farooqi et al. 2020).

\subsection{Traffic density measurement}

Traffic density was measured as the number of vehicles/h that occupied a segment of a road (Farooqi et al. 2020). The traffic density was calculated as number of vehicles/h by simple calculation as described by Paunovic et al. (2013) in which the number of vehicles was counted for 15 minutes at each location simultaneously with noise levels recording.

\subsection{Questionnaire based survey}

A questionnaire-based survey study was also conducted from the sampling locations of both cities to evaluate the non-auditory human health impacts of noise pollution. Further, to get better perception of noise impacts on human health, a questionnaire was filled by four age groups ( $\leq 20, \leq$ $40, \leq 60, \leq 80$ years) and their response was recorded in the form of "Agree", "Disagree" and "No comments". In addition to basic questions of health effects of noise, respondents were also asked about time of the day (Morning, Evening, After-noon, don't know) when there might be maximum noise pollution.

\section{Statistical analysis}

The collected data was analyzed as descriptive statistics. Pearson correlation analysis was performed to determine correlation between traffic density and noise levels. Moreover, Pearson product moment correlation was performed to determine the effect of age and sex on non-auditory health effects on the residents due to noise, and between the non-auditory health effects. ArcGIS software (version 10.4.1) was used to produce the maps and categorization of noise levels and traffic densities in the study areas. 


\section{Results}

\subsection{Noise levels in Chiniot and Jhang}

The descriptive statistics of noise pollution and relevant traffic density of various places of Jhnag and Chiniot are presented in Table 2 . The maximum noise level $\left(\mathrm{dB}_{\max }=103\right.$ with $\left.\mathrm{dB}_{\text {ave }}=88\right)$ was recorded at educational institutes followed by traffic intersections $\left(\mathrm{dB}_{\text {max }}=102\right.$ with $\mathrm{dB}_{\text {ave }}=$ 86) in Jhang whereas in Chiniot maximum noise level $\left(\mathrm{dB}_{\max }=120\right.$ with $\left.\mathrm{dB}_{\text {ave }}=89\right)$ at commercial places followed by traffic intersections $\left(\mathrm{dB}_{\text {max }}=\right.$ 115 with $\mathrm{dB}_{\mathrm{ave}}=93$ ). About $95 \%$ (74 out of 78) of the sampling locations in Chiniot and $82 \%$ (84 out of 103) locations in Jhang showed noise levels exceeding the permissible limits set by National Environmental Quality Standards (NEQS), Pakistan.

Table 2

Descriptive statistics of noise pollution and traffic density at selected areas of Jhang and Chiniot.

\begin{tabular}{|c|c|c|c|c|c|c|c|c|c|c|c|c|c|c|c|}
\hline \multirow[t]{2}{*}{ Cities } & \multirow{2}{*}{$\begin{array}{l}\text { Descriptive } \\
\text { Statistics }\end{array}$} & \multicolumn{3}{|c|}{ Noise pollution } & \multicolumn{11}{|c|}{ Traffic density } \\
\hline & & $\mathrm{CP}$ & TI & RR & HP & RA & IA & El & $\mathrm{CP}$ & TI & RR & HP & RA & IA & El \\
\hline \multirow[t]{6}{*}{ Jhang } & $\mathbf{N}$ & 6 & 34 & 9 & 10 & 18 & 8 & 18 & 6 & 34 & 9 & 10 & 18 & 8 & 18 \\
\hline & Mean & 85 & 86 & 60 & 64 & 70 & 85 & 88 & 3507 & 2899 & 1873 & 1877 & 2314 & 2068 & 2222 \\
\hline & Median & 86 & 89 & 62 & 61 & 74 & 83 & 89 & 3386 & 3025 & 1987 & 1494 & 2473 & 1825 & 2348 \\
\hline & Minimum & 78 & 59 & 39 & 46 & 49 & 74 & 74 & 3138 & 1799 & 293 & 1293 & 1464 & 1587 & 1426 \\
\hline & Maximum & 89 & 102 & 78 & 89 & 89 & 98 & 103 & 4294 & 3739 & 2894 & 3398 & 3104 & 3402 & 2585 \\
\hline & SD & 3.8 & 11 & 13.5 & 15.2 & 12.8 & 8.0 & 7.8 & 420.4 & 494.4 & 854.3 & 779.7 & 565.7 & 609.7 & 341.8 \\
\hline \multirow[t]{6}{*}{ Chiniot } & $\mathbf{N}$ & 13 & 17 & 9 & 10 & 10 & 7 & 12 & 13 & 17 & 9 & 10 & 10 & 7 & 12 \\
\hline & Mean & 89 & 93 & 80 & 89 & 88 & 86 & 83 & 2546 & 2949 & 2225 & 2769 & 1786 & 3228 & 2019 \\
\hline & Median & 80 & 100 & 80 & 89 & 89 & 84 & 83 & 2236 & 3103 & 2403 & 2714 & 1587 & 3042 & 2090 \\
\hline & Minimum & 70 & 70 & 60 & 78 & 73 & 78 & 73 & 1335 & 1492 & 1458 & 2453 & 1053 & 2705 & 1487 \\
\hline & Maximum & 120 & 115 & 95 & 99 & 103 & 98 & 93 & 4201 & 4032 & 3391 & 3127 & 2521 & 4241 & 2586 \\
\hline & SD & 18.28 & 13.8 & 12.3 & 7.3 & 9.4 & 7.2 & 6.3 & 928.3 & 715.1 & 690.5 & 233.6 & 480.4 & 503.9 & 360.1 \\
\hline \multicolumn{2}{|c|}{ Permissible limit (dB) } & $70 *$ & & \multicolumn{3}{|c|}{$55^{\star}, 45^{\star \star}$} & $\begin{array}{l}75^{\star} \\
70^{\star *}\end{array}$ & $\begin{array}{l}50^{*} \\
45^{\star *}\end{array}$ & & & & & & & \\
\hline
\end{tabular}

CP: Commercial places; TI: Traffic intersections; RR: Religious and recreational places; HP: Hospitals; RA: Residential areas; IA: Industrial areas; El: Educational institutes; NEQS-Pak*; WHO**

\subsection{Category based Noise levels in Chiniot and Jhang}

In case of Chiniot, maximum noise level within educational institutes was recorded at Bright Star Public Model School (93 dB), while minimum was found at Govt. Islah High School (73 dB) with traffic density of 2586 and 1487 vehicles/h, respectively. In Jhang, maximum noise level within educational institutes was recorded at Saifia Polytechnic Institute (103 dB), while minimum was recorded at Govt. Model High School (74 dB) with traffic density of 2539 and 2324 vehicles/h, respectively (Table 1S). In hospitals of Chiniot, maximum noise level was recorded at Pakistan Anti Goiter \& Patients Welfare Services ( $99 \mathrm{~dB})$, while minimum was found at DHQ hospital (78 dB) with traffic density of 3127 and 2453 vehicles/h, respectively. In Jhang, maximum noise level within hospitals was recorded at District TB hospital ( $89 \mathrm{~dB})$, while minimum was found at Shifa medical Centre (46 dB) with traffic density of 1294 and 1493 vehicles/h, respectively (Table 1S).

The maximum noise level within commercial areas in Chiniot was recorded at two places i.e. Azeem Ice Bar and Lucky Mall (120 dB), while minimum was found at NADRA office (70 dB) with traffic density of 4201, 3872 and 1724 vehicles/h, respectively. The maximum noise level within commercial areas of Jhang was recorded at Sabz Mandi ( $89 \mathrm{~dB}$ ), while minimum was recorded at Chambeli Market (78 dB) with traffic density of 3497 and 3138 vehicles/h, respectively (Table $2 \mathrm{~S}$ ). In industrial areas of Chiniot, maximum noise level was recorded at Kashmir Wood Industries (Pvt.) Ltd. (98 dB), while minimum was found at Janjua Agro-Industry $(78 \mathrm{~dB})$ with traffic density of 3023 and 3044 vehicles/h, respectively. The maximum noise level within industrial areas of Jhang was recorded at Hafiz Rice mills (98 dB), while minimum was found at Fawad Ghee Industries (74 dB) with traffic density of 3402 and 1587 vehicles/h, respectively (Table $2 S$ ).

The maximum noise level at traffic intersections in Chiniot was recorded at Chowk Shaheed (115 dB) while minimum was found at two sites i.e. Riaz Shah Road and Tibba Kamangran Road (70 dB) with traffic density of 3603 and 2042, 1830 vehicles/h, respectively. The maximum noise levels in 
Jhang was recorded at Khokha Chowk (102 dB) while minimum was recorded at Chiniot Road (59 dB) with traffic density of 3406 and 3124 vehicles/h, respectively (Table 3S).

The maximum noise level within residential areas in Chiniot was recorded in Satellite Town (103 dB) while minimum was noticed in Mohallah Kamangran (73 dB) with traffic density of 1643 and 1531 vehicles/h, respectively. In Jhang, the maximum noise level within residential areas was recorded at two sites i.e. Bhabhrana Mohallah and Sultan Wala Mohallah ( $89 \mathrm{~dB}$ ) while minimum at Officer Colony (49 dB) with traffic density of 2683, 3104 and 1464 vehicles/h, respectively (Table 4S). In religious and recreational areas of Chiniot, maximum noise level was recorded at Saeen Sukh Shrine (95 dB) while minimum was found at Chiniot Golf Club (60 dB) with traffic density of 3391 and 1458 vehicles/h, respectively. In Jhang, the maximum noise level was recorded at Masjid Haq Nawaz Shaheed (78 dB) while minimum was measured at Nawaz Shareef Park (39 dB) with traffic density of 2553 and 1864 vehicles/h, respectively (Table 4S).

Figure 3 describes noise intensity at each main location of Chiniot and Jhang urban areas. Industrial areas of both cities showed noise intensity in the range 80-100 dB, however, few places showed noise level under the permissible limit (75 dB) set by NEQS-Pak. Traffic intersections of both cities showed noise intensity of $<80,80-100$ and $>100 \mathrm{~dB}$ (Fig. 3), only three places in Jhang and two places in Chiniot have noise level within permissible limit of $70 \mathrm{~dB}$ (Table S3). The commercial area of Chiniot showed nosie level of $<80,80-100$ and $>100 \mathrm{~dB}$ whereas Jhang showed noise within $80-$ 100 and $>100 \mathrm{~dB}$. The educational institutes, hospitals, residential, religious, and recreational areas of both cities had noise level within $80-100$ and $>100 \mathrm{~dB}$, however, few samples in residential area of Chiniot showed noise level $>100 \mathrm{~dB}$.

\subsection{Relation between noise levels and traffic density $\left(T_{f}\right)$}

Linear regression analyses were performed to determine effect of traffic density on noise pollution. Results revealed that traffic density is directly related to noise pollution, however relation was weak at Jhang $\left(R^{2}=0.31\right.$; Fig. 2a) compared to Chiniot $\left(R^{2}=0.48\right.$; Fig. $\left.2 c\right)$. The relationship of traffic density and noise pollution varied with receiving community and showed a spatial variability. The regression analysis revealed strong linear relation between traffic density and noise pollution at hospitals $\left(R^{2}=0.79\right)$, residential areas $\left(R^{2}=0.77\right)$, whereas weak at industrial areas $\left(R^{2}=0.44\right)$, religious and recreational areas $\left(R^{2}=0.32\right)$, commercial places $\left(R^{2}=0.17\right)$ in Jhang (Fig. $\left.2 b\right)$. Similarly, strong linear relation between traffic density and noise pollution was found at commercial places $\left(R^{2}=0.85\right)$, traffic intersections $\left(R^{2}=0.77\right)$, religious and recreational areas $\left(R^{2}=0.61\right)$, hospitals $\left(R^{2}=0.53\right)$ and educational institutions $\left(R^{2}=0.50\right)$ in Chiniot (Fig. $\left.2 d\right)$.

\subsection{Survey based results}

In questionnaire-based survey, noise related human health effects like annoyance, depression, dizziness, headache, hypertension, hearing loss, physiological stress, sleeplessness, and tinnitus were studied in both Jhang and Chiniot cities. The respondents in this study were residents of both cities comprised of four age groups $(\leq 20, \leq 40, \leq 60, \leq 80$ years) and asked to fill answer against each question in either of three forms (Yes, No, No comment). Survey study revealed that all the respondents in Jhang suffered higher level of annoyance (53 vs. $51 \%)$, headache (67 vs. $64 \%)$, hypertension (71 vs. $70 \%$ ), and tinnitus (70 vs. $62 \%$ ) than residents of Chiniot due to noise, however, depression (45 vs. $47 \%)$, dizziness (61 vs. $65 \%)$, hearing loss (53 vs. $56 \%$ ), physiological stress ( 65 vs. $65 \%$ ), and sleeplessness ( 81 vs. $84 \%$ ) were higher in residents of Chiniot than Jhang (Table 3 ). Table 4 displays Pearson product moment correlation ( $r$ ) between age, sex, and noise-borne non-auditory effects assembled from both studied areas (Jhang and Chiniot). The age shows a variable response to noise-borne non-auditory health effects at both areas. Age caused significant positive effects on headache $(r=0.27, P<0.01)$ in the residents of Jhang, while headache $(r=0.58, P<0.01)$, depression $(r=0.28, P<0.01)$, hypertension $(r=$ $0.46, P<0.01)$, physiological stress $(r=0.34, P<0.01)$ in the residents of Chiniot. The negative correlation of sex found with depression $(r=-0.26, P<$ $0.01)$, hearing loss $(r=-0.25, P<0.05)$ while positive with physiological stress $(r=0.20, P<0.05)$. The correlation results revealed that depression caused dizziness $(r=0.31-0.38, P<0.01)$ and headache $(r=0.36-0.76, P<0.01)$ in the residents of Jhang and Chiniot. 
Table 3

Impacts of urban noise on citizen's health in Jhang and Chiniot (survey base response of respondents)

\begin{tabular}{|c|c|c|c|c|c|c|c|c|c|c|c|c|}
\hline \multirow[t]{3}{*}{ Health impacts } & \multicolumn{12}{|c|}{ Age group (years) of interviewed citizens of Jhang $(n=100)$} \\
\hline & $\leq 20$ & $\leq 40$ & $\leq 60$ & $\leq 80$ & $\leq \mathbf{2 0}$ & $\leq 40$ & $\leq 60$ & $\leq 80$ & $\leq 20$ & $\leq 40$ & $\leq 60$ & $\leq 80$ \\
\hline & \multicolumn{4}{|c|}{ Yes (\%) } & \multicolumn{4}{|c|}{ No (\%) } & \multicolumn{4}{|c|}{ No comment (\%) } \\
\hline Annoyance & 21 & 13 & 10 & 9 & 11 & 14 & 7 & 4 & 4 & 3 & 3 & 1 \\
\hline Depression & 2 & 22 & 12 & 9 & 13 & 11 & 10 & 4 & 8 & 6 & 3 & 0 \\
\hline Dizziness & 1 & 19 & 16 & 25 & 6 & 5 & 8 & 7 & 4 & 3 & 4 & 2 \\
\hline Headache & 6 & 19 & 9 & 33 & 13 & 8 & 4 & 4 & 3 & 0 & 0 & 1 \\
\hline Hypertension & 3 & 15 & 33 & 20 & 8 & 4 & 8 & 2 & 3 & 1 & 1 & 2 \\
\hline Hearing Loss & 0 & 10 & 14 & 29 & 0 & 8 & 12 & 6 & 11 & 1 & 7 & 2 \\
\hline Phys. Stress & 3 & 16 & 32 & 14 & 3 & 9 & 12 & 1 & 4 & 3 & 2 & 1 \\
\hline Sleeplessness & 8 & 21 & 32 & 20 & 3 & 2 & 4 & 5 & 3 & 0 & 1 & 1 \\
\hline \multirow[t]{2}{*}{ Tinnitus } & 0 & 13 & 34 & 23 & 4 & 9 & 10 & 2 & 3 & 2 & 0 & 0 \\
\hline & \multicolumn{12}{|c|}{ Age group (years) of interviewed citizens of Chiniot $(n=100)$} \\
\hline Annoyance & 24 & 8 & 8 & 11 & 12 & 15 & 9 & 4 & 3 & 2 & 3 & 1 \\
\hline Depression & 0 & 21 & 15 & 11 & 17 & 13 & 15 & 5 & 0 & 2 & 1 & 0 \\
\hline Dizziness & 0 & 24 & 17 & 24 & 4 & 7 & 8 & 9 & 6 & 0 & 1 & 0 \\
\hline Headache & 4 & 21 & 14 & 25 & 15 & 11 & 2 & 2 & 0 & 0 & 0 & 6 \\
\hline Hypertension & 1 & 19 & 22 & 28 & 15 & 5 & 2 & 2 & 1 & 2 & 1 & 2 \\
\hline Hearing Loss & 0 & 9 & 13 & 34 & 2 & 10 & 7 & 5 & 4 & 5 & 10 & 1 \\
\hline Phys. Stress & 0 & 14 & 35 & 16 & 6 & 11 & 12 & 3 & 1 & 0 & 0 & 2 \\
\hline Sleeplessness & 11 & 23 & 27 & 23 & 1 & 2 & 5 & 5 & 0 & 1 & 0 & 2 \\
\hline Tinnitus & 0 & 11 & 22 & 29 & 5 & 5 & 12 & 5 & 5 & 3 & 0 & 3 \\
\hline
\end{tabular}


Table 4

Pearson product-moment correlation coefficients ( $r$ ) for noise-related and health variables of Jhang and Chiniot.

\begin{tabular}{|c|c|c|c|c|c|c|c|c|c|c|c|}
\hline Jhang $(n=100)$ & AGE & SEX & ANN & DEP & DIZ & HED & HYP & HEL & PHS & SLL & TIN \\
\hline Age & 1.00 & & & & & & & & & & \\
\hline Sex & $0.19 *$ & 1.00 & & & & & & & & & \\
\hline Annoyance (ANN) & 0.00 & -0.12 & 1.00 & & & & & & & & \\
\hline Depression (DEP) & -0.06 & $-0.26 * \star$ & -0.03 & 1.00 & & & & & & & \\
\hline Headache (HED) & $0.27 * \star$ & -0.02 & 0.20 & $0.36^{\star \star}$ & 0.22 & 1.00 & & & & & \\
\hline Hypertension (HYP) & 0.19 & 0.13 & 0.08 & 0.14 & 0.14 & -0.03 & 1.00 & & & & \\
\hline Hearing Loss (HEL) & $-0.28 * \star$ & -0.03 & 0.17 & -0.21 & 0.02 & $-0.29 *$ & $-0.26^{\star}$ & 1.00 & & & \\
\hline Physiological Stress (PHS) & -0.02 & 0.15 & $0.31 * \star$ & -0.13 & $0.37 * \star$ & -0.10 & $0.28 * \star$ & 0.04 & 1.00 & & \\
\hline \multicolumn{12}{|l|}{ Chiniot $(n=100)$} \\
\hline Age & 1.00 & & & & & & & & & & \\
\hline Sex & $0.19 *$ & 1.00 & & & & & & & & & \\
\hline Annoyance (ANN) & 0.02 & -0.02 & 1.00 & & & & & & & & \\
\hline Physiological Stress (PHS) & $0.34 * \star$ & $0.20 *$ & 0.09 & 0.17 & 0.12 & 0.23 & $0.35^{\star \star}$ & -0.08 & 1.00 & & \\
\hline Sleeplessness (SLL) & -0.05 & -0.11 & $-0.33^{\star \star}$ & 0.11 & 0.09 & $0.30 * *$ & -0.06 & -0.20 & 0.05 & 1.00 & \\
\hline Tinnitus (TIN) & -0.00 & 0.10 & 0.07 & 0.13 & $0.49 * \star$ & $-0.45^{\star \star}$ & -0.10 & $-0.34 * \star$ & 0.09 & 0.16 & 1.00 \\
\hline \multicolumn{12}{|c|}{ * Correlation is significant at the $P<0.05$ level (2-tailed). } \\
\hline ** Correlation is significant & he $P<0$ & level & ailed). & & & & & & & & \\
\hline
\end{tabular}

The respondents of four age groups were interviewed about the specific times (morning, afternoon, evening, don't know) when they are exposed to maximum level of noise (Table 5). Out of 400 respondents in Jhang, 195 people (48\%) responded that they were exposed to maximum noise at afternoon timings. This might be due to the high traffic at school-off timing, 104 (26\%) said that they were exposed to high noise at morning time and 67 people (17\%) told that they were exposed to maximum noise at evening timings while 34 people (9\%) gave no response. Similar response was obtained in Chiniot where, out of 400 respondents, 223 respondents (56\%) were exposed to maximum noise level at afternoon timings. It was attributed to the high traffic due to school-off timing, 92 respondents (23\%) told that they were exposed to high noise at morning time and 54 (14\%) told at evening timings while 31 people (7\%) gave no response. According to the above results, the citizens of both the cities were exposed to maximum urban noise levels during afternoon time with the order afternoon $>$ morning $>$ evening. 
Table 5

Citizens perceptions about time of the day, when they are exposed to maximum noise levels in Jhang and Chiniot (survey base response of respondents)

\begin{tabular}{|clll|}
\hline Age Groups & \multicolumn{2}{l|}{ People perceptions in Jhang } & \multicolumn{2}{l|}{ People perceptions in Chiniot } \\
\cline { 2 - 4 } Morning Afternoon Evening No comment Afternoon Evening No comment
\end{tabular}

\begin{tabular}{|lllllllll|}
\hline $\mathbf{2 0}$ & 31 & 48 & 15 & 06 & 34 & 45 & 13 & 08 \\
\hline $\mathbf{4} \mathbf{4 0}$ & 25 & 40 & 20 & 15 & 21 & 51 & 19 & 09 \\
\hline $\mathbf{6 0}$ & 35 & 49 & 11 & 05 & 24 & 61 & 13 & 02 \\
\hline $\mathbf{8 0}$ & 13 & 58 & 21 & 08 & 13 & 66 & 09 & 12 \\
\hline
\end{tabular}

\section{Discussion}

Noise pollution is an emerging threat to developed and under-developed countries, therefore, it is obvious to collect baseline data for effective management of expanding urbanization. Here, in this study, we have tried to determine noise intensity at various gathering places of Jhang and Chiniot urban areas. In both the study areas, we found that most of the sites exceeded the SPL limits prescribed by the NEQS-Pak and WHO (Table 2). For instance, in commercial areas of Jhang and Chiniot we found 89 and $120 \mathrm{~dB}$ noise pollution, respectively and traffic intersections we found 102 and $115 \mathrm{~dB}$ against the permissible limit of $70 \mathrm{~dB}$, religious and recreational areas we found 78 and $95 \mathrm{~dB}$ and hospitals 89 and $99 \mathrm{~dB}$ against the permissible limit of $55 \mathrm{~dB}$ and $45 \mathrm{~dB}$ set by NEQS-Pak and WHO, respectively. The noise level 89 and $103 \mathrm{~dB}$ observed in residential areas against the permissible limit of $65 \mathrm{~dB}$, while $98 \mathrm{~dB}$ in industrial areas of both cities against the permissible limit of $75 \mathrm{~dB}, 70 \mathrm{~dB}$ and $65 \mathrm{~dB}$ set by NEQS-Pak, USEPA and WHO, respectively. The educational institutes had noise level of 103 and $91 \mathrm{~dB}$ respectively against the permissible limits of $50 \mathrm{~dB}$ and 45 $\mathrm{dB}$ set by NEQS-Pak and WHO, respectively. These findings confirmed that both cities have noise pollution levels higher than permissible limits of NEQS-Pak and WHO.

A strong association between noise level and traffic density has been observed (Fig. 2). This outcome remained consistent in all the categorized areas included in the study and in line with the previous findings (Doygun et al. 2016; Purwaningsih et al. 2018). The high traffic density is responsible for high noise pollution (Khan et al. 2018), whereas urban noise is significantly decreased in low traffic areas (Tezel et al. 2019). The present study also confirmed association of noise and traffic. In the study, the traffic density is positively correlated with noise pollution in both cities, however, strong correlation existed in Chiniot. This consistency is due to the association between noise and different traffic related noise types like horns (Muralidharan et al. 2018; Alsina-Pagès et al. 2019; Chang et al. 2019), honking (Vijay et al. 2018; Aditya and Chowdary 2020) and engine ignition sounds (Little 2018; Manea et al. 2017). It might be due to the heavy traffic (dumpers) which transported rocks and crushed stones from Chiniot to all over the country. These dumpers are not usually seen in Jhang. Another reason is the central position of Chiniot, which facilitates movement of heavy traffic to Lahore, Faisalabad, Sargodha and Jhang. Chiniot city is the hub of small industry, stone crushing industry and wood artwork, therefore, many people visit this city on frequent basis for business purpose which increases traffic frequency and thus high noise pollution. The industries are significant source of noise pollution, which is increased with increase in the industrial processes (Kannan et al. 2017; Deb et al. 2018; Kim et al. 2019). The high level of noise in Chiniot is due to working of small industry and our results revealed that negative correlation $\left(R^{2}=\right.$ 0.04) existed between noise level and traffic frequency in industrial set up of Chiniot (Fig. $2 \mathrm{~d}$ ), which conferred that traffic did not the source of noise rather industrial operations might be the possible reason. The dense population per unit area in the city (Table 1) is also the reason behind high noise. Govt. should take stringent action to control population growth rate in both cities, ensure maintenance of vehicles and ban on pressure horns in urban areas. Based on the noise level readings of every area category, we divided them into equal intervals $(40-50,51-60,61-70,71-80,81-90$ and $\geq$ 90). Only 5 areas ( 1 residential and 2 both in hospitals and religious and recreational areas in Jhang) were lying in $40-50 \mathrm{~dB}$ category and most of the areas $(n=25)$ lying in above $90 \mathrm{~dB}$ category. Even worse condition was seen in Chiniot where no site had noise levels between $40-50 \mathrm{~dB}$ while only 1 site lied in between $51-60$ and above half $(n=32)$ were lying in areas with more than $90 \mathrm{~dB}$ noise levels (Table 6). 
Table 6

Categories of noise on sampling locations of Jhang and Chiniot.

\begin{tabular}{|c|c|c|c|c|c|c|c|c|c|}
\hline \multirow[t]{2}{*}{ Areas of Jhang } & \multicolumn{7}{|c|}{ Categories } & \multicolumn{2}{|c|}{$\begin{array}{l}\text { Standard limit } \\
\text { (dB) }\end{array}$} \\
\hline & $\leq 50$ & $\leq 60$ & $\leq 70$ & $\leq 80$ & $\leq 90$ & $>90$ & $\mathbf{N}$ & NEQS & WHO \\
\hline Commercial Areas & - & - & - & 1 & 5 & - & 34 & 70 & 60 \\
\hline Traffic Intersections & - & 1 & 2 & 8 & 7 & 16 & 18 & 70 & \\
\hline Religious and Recreational Areas & 2 & 2 & 2 & 3 & - & - & 9 & 55 & 45 \\
\hline Hospitals & 2 & 3 & 2 & 1 & 2 & - & 10 & 55 & 45 \\
\hline Residential Areas & 1 & 4 & 2 & 7 & 4 & - & 6 & 55 & 45 \\
\hline Industrial Areas & - & - & - & 2 & 4 & 2 & 18 & 75 & 70 \\
\hline Educational Areas & - & - & - & 3 & 8 & 7 & 8 & 50 & 45 \\
\hline \multicolumn{10}{|l|}{ Areas of Chiniot } \\
\hline Commercial Areas & - & - & 1 & 6 & 2 & 4 & 13 & 70 & 60 \\
\hline Traffic Intersections & - & - & 2 & 2 & 2 & 11 & 17 & 70 & \\
\hline Religious and Recreational Areas & - & 1 & - & 3 & 1 & 3 & 9 & 55 & 45 \\
\hline Hospitals & - & - & - & 1 & 4 & 5 & 10 & 55 & 45 \\
\hline Residential Areas & - & - & - & 2 & 3 & 5 & 10 & 55 & 45 \\
\hline Industrial Areas & - & - & - & 1 & 4 & 2 & 7 & 75 & 70 \\
\hline Educational Areas & - & - & - & 3 & 7 & 2 & 12 & 50 & 45 \\
\hline
\end{tabular}

Non-auditory impact of noise pollution on public health is obvious. Survey study revealed that all the respondents in Jhang suffered higher level of annoyance, headache, hypertension, and tinnitus than residents of Chiniot due to noise, however, depression, dizziness, hearing loss, physiological stress and sleeplessness were higher in residents of Chiniot than Jhang (Table 3). Several previous study indicated different diseases due to noise, for example people living in noisy city areas are more depressed (Zijlema et al. 2016; He et al. 2019; Diaz et al. 2020), face anxiety (Afarinesh et al. 2018; Diaz et al. 2020), headache (Yadav and Bilas 2017; Nazneen et al. 2020), increased heart beat rate (Islam et al. 2016; Nassur et al. 2019), annoyance (Paiva et al. 2019), sleeplessness (Farooqi et al. 2020), hypertension (Tonne et al. 2016) and psychological stress (Palma et al. 2019; Yarar et al. 2019). The Pearson product moment correlation revealed that age had positive impacts on noise-borne non-auditory health effects in humans especially headache, depression, hypertension, and physiological stress are directly related to age, however, hearing loss due to noise is more common in children (Table 4). Moreover, noise-borne non-auditory health effects are found in both males and females indicating these effects are independent to gender. Pearson product moment correlation results inferred spatial impacts of noise-borne non-auditory health effects on the residents of both areas. Our presented results are in line with some of the previous studies conducted in other cities and geographical zones of the world (Table 7); as multiple studies have described the negative impact of noise levels on the nearby community, citizens, patients and students in the study areas. These results also indicate that there is a significant relationship between the traffic density and the urban noise levels. 
Table 7

Comparative overview of noise pollution monitoring, sources and associated health risks

\begin{tabular}{|c|c|c|c|c|}
\hline City, Country & $\begin{array}{l}\text { Noise Levels } \\
\text { (dB) }\end{array}$ & Source & Health Impacts & References \\
\hline $\begin{array}{l}\text { Thessaloniki, } \\
\text { Greece }\end{array}$ & $51-77.4$ & Traffic & Cardiovascular diseases & (Begou et al. 2020) \\
\hline Barcelona, Spain & $35-80$ & Traffic & Mortality & (Barceló et al. 2016) \\
\hline São Paulo, Brazil & $66-78$ & Traffic & Annoyance & (Paiva et al. 2019) \\
\hline New York, USA & $\geq 76$ & Traffic & Hearing problems & (King et al. 2016) \\
\hline Tehran, Iran & $\geq 82$ & Traffic & harmful effects on the citizens & $\begin{array}{l}\text { (Abbaspour et al. } \\
\text { 2015) }\end{array}$ \\
\hline London, UK & $60-\geq 65$ & Traffic & Hypertension, Angina, diabetes & (Tonne et al. 2016) \\
\hline Tokat, Turkey & $\geq 65$ & Traffic & Nervous frailty, anxiety, dizziness & (Ozer et al. 2009) \\
\hline $\begin{array}{l}\text { Port-Harcourt, } \\
\text { Nigeria }\end{array}$ & $\otimes 97.6$ & Traffic & Hypertension, hearing disturbance and high blood pressure & $\begin{array}{l}\text { (Ononugbo et al. } \\
\text { 2017) }\end{array}$ \\
\hline $\begin{array}{l}\text { Faisalabad, } \\
\text { Pakistan }\end{array}$ & \$101 & Traffic & $\begin{array}{l}\text { Hypertension, hearing disturbance, headache, sleep disturbances and } \\
\text { dizziness }\end{array}$ & (Farooqi et al. 2020) \\
\hline Jhang, Pakistan & 103 & Traffic & Hypertension, headache, sleep disturbances and dizziness, tinnitus & This study \\
\hline Chiniot, Pakistan & 120 & & & \\
\hline
\end{tabular}

\section{Conclusion And Recommendations}

Traffic noise from a city street can affect the quality of life in noise-sensitive locations. This study revealed that traffic and industrial operation are the two main sources of noise in both studied cities, however the impact was higher in Chiniot (>95\% sampling locations) than Jhang (> $82 \%$ sampling locations) exceeding the permissible limits set by NEQS-Pak. The traffic density is directly proportional to noise pollution $\left(R^{2}=0.50-0.85\right.$ in Chiniot while $\mathrm{R}^{2}=0.17-0.79$ in Jhang). The survey-based results conferred health impacts of noise pollution on residents of both cities. Keeping in view the psychological and physiological health effects of urban traffic noise, reduction of exposure to noise is an important public health measure. There are several ways to avoid or minimize noise impacts to the maximum extent practicable. The best way to minimize exposure to a noise for new objects is to establish the zoning during planning and designing processes with relevant distance between a source, and building, as a recipient of noise. Traffic sources of noise and noise-sensitive population are normally incompatible unless effective measures are taken to reduce environmental noise. The compatibility depends on a good sound insulation of buildings. Noise from the outer lining of the building must be planned and implemented so that the noise level does not exceed the permissible limits. In environments, where noise effects cannot be readily reduced to a level of less significance by acoustical improvements, noise avoidance and mitigation measures of an existing building may be put in place directly with different noise barriers. As vegetation provides noise attenuation, it can influence noise impact potential for existing situation of noise. In this case, a plant material is economically, aesthetically, and psychologically the most suitable for the better acoustical performance of the buildings. The proposed measures ensure acoustic comfort and health for all the occupants of the buildings. At the end, there should be incorporation of appropriate preventive measures to minimize the noise impacts, as required under Pak-EPA and WHO recommendations.

\section{Declarations}

\section{Competing interests}

The authors declare that they have no known competing financial interests or personal relationships that could have appeared to influence the work reported in this paper.

\section{Ethics approval and consent to participate}

This study does not involve any humans or animals during experimentation, so it does not applicable in this study.

\section{Consent for publication}

Survey was conducted in local community of both cities and questionnaire was filled with their verbal consent.

\section{Phys. Stress}


Physiological stress

\section{Funding}

This research is funded by the Ministry for Scientific and Technological Development, Higher Education and Information Society of Republic of Srpska (19/6-020/961-96/18) in the frame of project "Environmental assessment correlated with the environmental risks in the urban area".

\section{Authors contributions}

ZUR, IA, PI: conceptualization, writing - original draft preparation, methodology, investigation; NZ: methodology, investigation; MI, MFS: methodology, resources \& analysis; IA, PI: writing- reviewing and editing, resources, supervision.

\section{References}

Abbaspour M, Karimi E, Nassiri P, Monazzam MR, Taghavi L (2015) Hierarchal assessment of noise pollution in urban areas - A case study. Transportation Research Part D: Transport and Environment 34:95-103. doi:https://doi.org/10.1016/j.trd.2014.10.002 Aditya K, Chowdary V (2020) Influence of honking on the road traffic noise generated at urban rotaries for heterogeneous traffic. Environmental and Climate Technologies 24(1):23-42 Afarinesh MR, Akhtardanesh B, Haghpanah T, Golshan F, Meftahi GH, Ghanbarpour N, Fakhri A, Sheikhshoaei S, Sheibani V (2018) Urban traffic noise pollution disturbs spatial learning and memory and increases anxiety-like behavior in adult male rats. Physiology and Pharmacology 22 (3):146-154 Alsina-Pagès RM, Orga F, Alías F, Socoró JC (2019) A WASN-based suburban dataset for anomalous noise event detection on dynamic road-traffic noise mapping. Sensors 19 (11):2480 Auger N, Duplaix M, Bilodeau-Bertrand M, Lo E, Smargiassi A (2018) Environmental noise pollution and risk of preeclampsia. Environmental Pollution 239:599-606 Bamane P, Kumthekar MB, Sharma OP (2019) Review paper on noise control in industry. http://dx.doi.org/10.2139/ssrn.3368199 Barceló MA, Varga D, Tobias A, Diaz J, Linares C, Saez M (2016) Long term effects of traffic noise on mortality in the city of Barcelona, 2004-2007. Environmental Research 147:193-206.

doi:https://doi.org/10.1016/j.envres.2016.02.010 Begou P, Kassomenos P, Kelessis A (2020) Effects of road traffic noise on the prevalence of cardiovascular diseases: The case of Thessaloniki, Greece. Science of the Total Environment 703:134477.

doi:https://doi.org/10.1016/j.scitotenv.2019.134477 Braat-Eggen, PE, van Heijst A, Hornikx M, Kohlrausch A (2017) Noise disturbance in open-plan study environments: A field study on noise sources, student tasks and room acoustic parameters. Ergonomics 60(9):1297-1314 Bridger JF, Stewart ND, Gagliardi J, Mahajan S, Schafer F (2019) Unusual case studies-Investigating outdoor and indoor sources of community noise. The Journal of the Acoustical Society of America 146 (4):2913-2913 Brink M, Schäffer B, Vienneau D, Pieren R, Foraster M, Eze IC, Rudzik F, Thiesse L, Cajochen C, Probst-Hensch N, Röösli M, Wunderli JM (2019) Self-reported sleep disturbance from road, rail and aircraft noise: Exposure-response relationships and effect modifiers in the SiRENE study. Int J Environ Res Public Health 16(21): 4186. doi: 10.3390/ijerph1621418616 (21):4186 Brown A, Muhar A (2004) An approach to the acoustic design of outdoor space. Journal of Environmental Planning and Management 47 (6):827-842 Cai M, Lan Z, Zhang Z, Wang H (2019) Evaluation of road traffic noise exposure based on high-resolution population distribution and grid-level noise data. Building and Environment 147:211-220 Chang TY, Liang CH, Wu CF, Chang LT (2019) Application of land-use regression models to estimate sound pressure levels and frequency components of road traffic noise in Taichung, Taiwan. Environment International 131:104959 Cramer J, Jørgensen JT, Sørensen M, Backalarz C, Laursen JE, Ketzel M, Hertel O, Jensen SS, Simonsen MK, Bräuner EVJEr (2019) Road traffic noise and markers of adiposity in the Danish Nurse Cohort: A cross-sectional study. Environ. Res. 172:502-510 Deb AK, Chowdhury M, Hossain MI, Sarker MR (2018) Assessment of noise, temperature, light intensity and their impacts on workers in footwear and leather products industries of Bangladesh. Journal of Environmental Science, Toxicology and Food Technology 12:25-31 Defourny J, Aghaie A, Perfettini I, Avan P, Delmaghani S, Petit CJ (2019) Pejvakin-mediated pexophagy protects auditory hair cells against noise-induced damage. Proceedings of the National Academy of Sciences 116 (16):8010-8017 Díaz J, López-Bueno JA, López-Ossorio JJ, Gónzález JL, Sánchez F, Linares C (2020) Short-term effects of traffic noise on suicides and emergency hospital admissions due to anxiety and depression in Madrid (Spain). Science of the Total Environment 710: 136315 Doygun N, Doygun H, Gozcu M (2016) Evaluating and mapping traffic-induced noise pollution in urban parks in the city of Kahramanmaraş, Turkey. Fresenius Environmental Bulletin 25 (12), 5202-5207 Farooqi ZUR, Nasir MS, Nasir A, Zeeshan N, Ayub I, Rashid H, Qamar MU, Sarwar A, Akram MA (2017) Evaluation and analysis of traffic noise in different zones of Faisalabad - an industrial city of Pakistan. Geology, Ecology, and Landscapes 1 (4):232-240.

doi:10.1080/24749508.2017.1389454 Farooqi ZUR, Sabir M, Latif J, Aslam Z, Ahmad HR, Ahmad I, Imran M, Ilić P (2020) Assessment of noise pollution and its effects on human health in industrial hub of Pakistan. Environmental Science and Pollution Research 27 (3):2819-2828. doi:10.1007/s11356-019-07105-7 Fedorko G, Liptai P Molnár V (2018) Proposal of the methodology for noise sources identification and analysis of continuous transport systems using an acoustic camera. Engineering Failure Analysis 83:30-46. Fecht D, Hansell AL, Morley D, Dajnak D, Vienneau D, Beevers S, Toledano MB, Kelly FJ, Anderson HR, Gulliver J (2016) Spatial and temporal associations of road traffic noise and air pollution in London: Implications for epidemiological studies. Environment International 88:235-242 Fredianelli L, Carpita S, Licitra G (2019) A procedure for deriving wind turbine noise limits by taking into account annoyance. Science of the Total Environment, 648, 728-736. Garg N, Sinha A, Gandhi V, Bhardwaj R, Akolkar A (2016) A pilot study on the establishment of national ambient noise monitoring network across the major cities of India. Applied Acoustics 103:20-29 Hahad O, Kröller-Schön S, Daiber A, Münzel TJ (2019) The cardiovascular effects of noise. Dtsch Arztebl Int. 116(14): 245-250. Hahad O, Beutel M, Gori T, Schulz A, Blettner M, Pfeiffer N Münzel T (2018). Annoyance to different noise sources is associated with atrial fibrillation in the Gutenberg Health Study. International Journal of Cardiology 264:79-84. Hashim ZHM, Wan Ahmad WA, Alisaputri ML 
3(1), 572-572. He S, Smargiassi A, Low N, Bilodeau-Bertrand M, Ayoub A, Auger N (2019) Residential noise exposure and the longitudinal risk of hospitalization for depression after pregnancy: Postpartum and beyond. Environmental Research 170:26-32 Hicks Pries CE, Castanha C, Porras RC, Torn MS (2017) The whole-soil carbon flux in response to warming. 355 (6332):1420-1423. doi:10.1126/science.aal1319\%J Science Ishikawa T, Tatsumoto M, Maki K, Mitsui M, Hasegawa H, Hirata KJIM (2019) Identification of Everyday Sounds Perceived as Noise by Migraine Patients.22062218 Islam M, Rahman M, Roy B, Hossen M (2016) Noise Pollution at Health Care Centers in Mymensingh City of Bangladesh. Journal of Environmental Science and Natural Resources 9 (1):87-90 Javaherian M, Abedi A, Khoeini F, Abedini Y, Asadi A, Ghanjkhanloo EJG-JoAS (2018) Survey of Noise Pollution in Zanjan, and Comparing them with Standards. 1 (1):01-08 Jørgensen JT, Bräuner EV, Backalarz C, Laursen JE, Pedersen TH, Jensen SS, Ketzel M, Hertel O, Lophaven SN, Simonsen MKJEhp (2019) Long-Term Exposure to Road Traffic Noise and Incidence of Diabetes in the Danish Nurse Cohort. 127 (5):057006 Kang J (2006) Urban sound environment. CRC Press, Khan J, Ketzel M, Kakosimos K, Sørensen M, Jensen SS (2018) Road traffic air and noise pollution exposure assessment-A review of tools and techniques. Science of The Total Environment 634:661676 Kim K, Shin J, Oh M, Jung JK (2019) Economic value of traffic noise reduction depending on residents annoyance level. Environmental Science and Pollution Research 26(7):7243-7255 King EA, Bourdeau EP, Zheng XYK, Pilla F (2016) A combined assessment of air and noise pollution on the High Line, New York City. Transportation Research Part D: Transport and Environment 42:91-103. doi:https://doi.org/10.1016/j.trd.2015.11.003 Kujawa SG, Liberman MCJHr (2019) Translating animal models to human therapeutics in noise-induced and age-related hearing loss. Little AG (2018) Sound the alarm: motorboat disturbance to fish embryos depends on engine type. Conservation physiology 6 (1):coy064 Liu J, Song C, Zhao J, Ji PJITol, Measurement (2019) Manifold-preserving sparse graph based ensemble FDA for industrial label-noise fault classification. Mahmud MS, Basak RJAJoE, Ecology (2019) An Assessment of Noise Levels in Sylhet City Corporation, Bangladesh.1-11 Manea L, Manea A, Florea D, Tarulescu S Road traffic noise pollution analysis for Cernavoda city. In: IOP Conference Series: Materials Science and Engineering, 2017. vol 1. IOP Publishing, p 012057 Münzel T, Sørensen M (2017) Noise pollution and arterial hypertension. European Cardiology Review 12 (1):26 Muralidharan L, Gaur S, Muralidharan C (2018) A study on noise pollution in Mumbai, India and its adverse impact on human health. IJRAR, 5 (3): 505508 Nassur AM, Léger D, Lefèvre M, Elbaz M, Mietlicki F, Nguyen P, Evrard AS (2019) Effects of aircraft noise exposure on heart rate during sleep in the population living near airports. International Journal of Environmental Research and Public Health 16(2):269. Nazneen S, Raza A, Khan S (2020) Assessment of noise pollution and associated subjective health complaints and psychological symptoms: analysis through structure equation model. Environ Sci Pollut Res Int.27(17):21570-21580. Ng C, Hui C (2008) Low frequency sound insulation using stiffness control with honeycomb panels. Applied Acoustics 69 (4):293-301 Ononugbo C, Avwiri G, Osuyali C (2017) Assessment of noise pollution level of Trans-Amadi Industrial Layout, Port-Harcourt City Rivers State, Nigeria. Scientia Africana 16 (1) Ozer S, Yilmaz H, Yesil M, Yesil P (2009) Evaluation of noise pollution caused by vehicles in the city of Tokat, Turkey. Scientific Research and Essay 4 (11):1205-1212 Paiva KM, Cardoso MRA, Zannin PHT (2019) Exposure to road traffic noise: Annoyance, perception and associated factors among Brazil's adult population. Science of the Total Environment 650:978-986.

doi:https://doi.org/10.1016/j.scitotenv.2018.09.041 Palma J, Magalhães M, Correia M, Andrade JP (2019) Effects of anthropogenic noise as a source of acoustic stress in wild populations of Hippocampus guttulatus in the Ria Formosa, south Portugal. Aquatic Conservation: Marine and Freshwater Ecosystems 29 (5):751-759 Paunovic K, Belojevic G, Jakovljevic B (2013) Blood pressure of urban school children in relation to roadtraffic noise, traffic density and presence of public transport. Noise Health. 15 (65):253-260. doi:10.4103/1463-1741.113521 Picaut J, Fortin N, Bocher E, Petit G, Aumond P, Guillaume GJ (2019) An open-science crowdsourcing approach for producing community noise maps using smartphones. Building and Environment 148:20-33 Purwaningsih NMS, Alli MSA, Shams OU, Ghani JM, Ayyaturai S, Sailan AT, Sinon SHM (2018) Analysis of noise pollution: A case study of Malaysia's university. Journal of International Dental and Medical Research 11 (1):330-333 Shore SE, Wu CJN (2019) Mechanisms of Noise-Induced Tinnitus: Insights from Cellular Studies. Neuron 103 (1):8-20 Tezel MN, Sari D, Ozkurt N, Keskin SS (2019) Combined NOx and noise pollution from road traffic in Trabzon, Turkey. Science of the Total Environment 696:134044 Tonne C, Halonen JI, Beevers SD, Dajnak D, Gulliver J, Kelly FJ, Wilkinson P, Anderson HR (2016) Long-term traffic air and noise pollution in relation to mortality and hospital readmission among myocardial infarction survivors. International Journal of Hygiene and Environmental Health 219 (1):72-78.

doi:https://doi.org/10.1016/j.ijheh.2015.09.003 Tonne C, Milà C, Fecht D, Alvarez M, Gulliver J, Smith J, Beevers S, Ross Anderson H, Kelly F (2018) Socioeconomic and ethnic inequalities in exposure to air and noise pollution in London. Environment International 115:170-179. Vijay R, Chakrabarti T, Gupta R (2018) Characterization of traffic noise and honking assessment of an Indian urban road. Fluctuation and Noise Letters 17 (04):1850031 Wang W, Zhang LS, Zinsmaier AK, Patterson G, Leptich EJ, Shoemaker SL, Yatskievych TA, Gibboni R, Pace E, Luo H, Zhang J, Yang S, Bao S (2019) Neuroinflammation mediates noise-induced synaptic imbalance and tinnitus in rodent models. PLOS Biology 17 (6):e3000307.

https://doi.org/10.1371/journal.pbio.3000307 Wilson DJ (2019) Community noise exposure and annoyance: A multilevel description. The Journal of the Acoustical Society of America 146(4):2910-2910. DOI: 10.1121/1.5137098 Wolniewicz K, Zagubień A (2015) Verifying traffic noise analysis calculation models. Polish Journal of Environmental Studies 24(6):2767-2772 Xu SY, Jiang C, Huang L (2019) Public health impacts from subway noise: Case study Hong Kong. The Journal of the Acoustical Society of America 145 (3):1867-1867. doi:10.1121/1.5101747 Yadav S, Bilas R (2017) Effect of noise pollution on exposed people of Gorakhpur City. Indian Journal of Scientific Research 8 (1):99-107 Yarar 0, Temizsoy E, Günay O (2019) Noise pollution level in a pediatric hospital. International Journal of Environmental Science and Technology 16(9):5107-5112 Yong JJ, Jik Lee P, Young Hong J, Cabrera D (2011) Non-auditory factors affecting urban soundscape evaluation. The Journal of the Acoustical Society of America 130 (6):3761-3770 Zeydabadi A, Askari J, Vakili M, Mirmohammadi SJ, Ghovveh MA, Mehrparvar AH (2019) The effect of industrial noise exposure on attention, reaction time, and memory. Int Arch Occup Environ Health. 92 (1):111-116 Zhang Y, Kang J, Kang J (2017) Effects of soundscape on the environmental restoration in urban natural environments. Noise Health 19 (87):65 Zheng X, Peng W, Hu M (2020) Airport noise and house prices: A quasi-experimental design study. Land Use Policy 90:104287. doi:https://doi.org/10.1016/j.landusepol.2019.104287 Zijlema WL, Wolf K, Emeny R, Ladwig K-H, Peters A, Kongsgård H, Hveem K, Kvaløy K, Yli-Tuomi T, Partonen T (2016) The association of air pollution and depressed mood in 70,928 individuals from four European cohorts. International Journal of Hygiene and Environmental Health 219 (2):212-219.

Page $12 / 14$ 


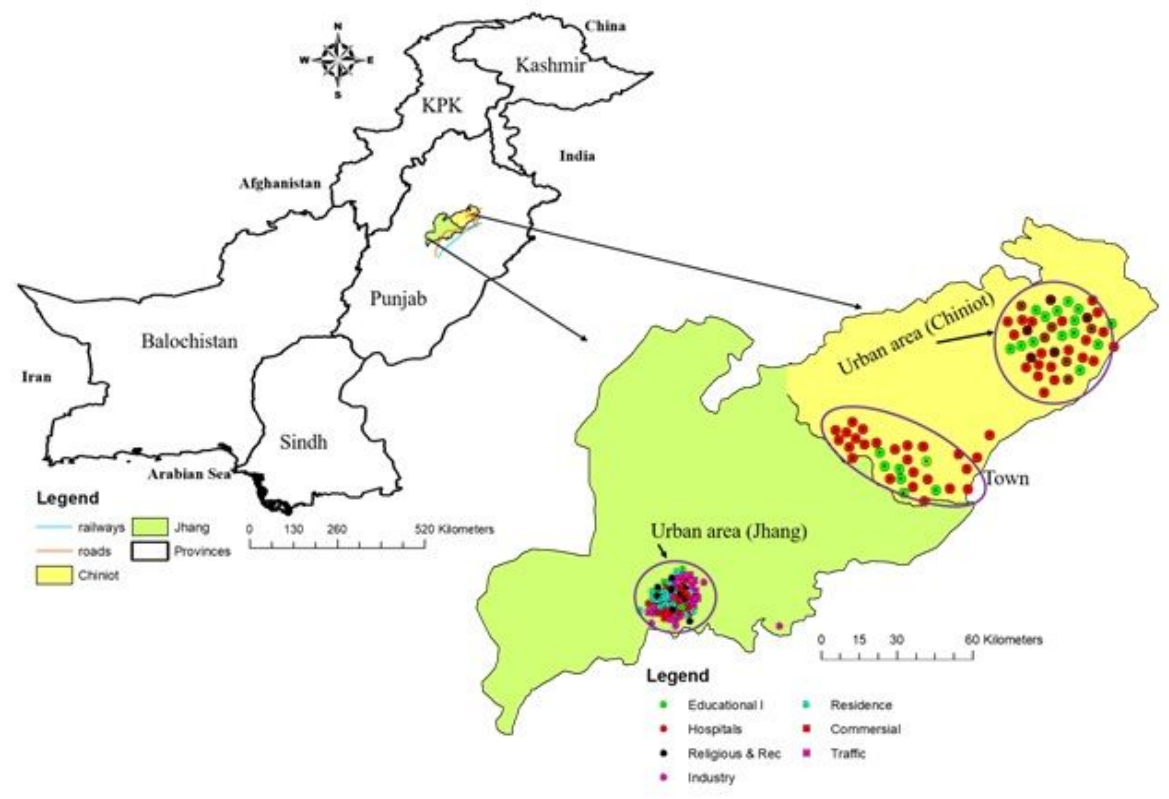

Figure 1

Sampling locations of Jhang (green) and Chiniot (yellow) urban areas
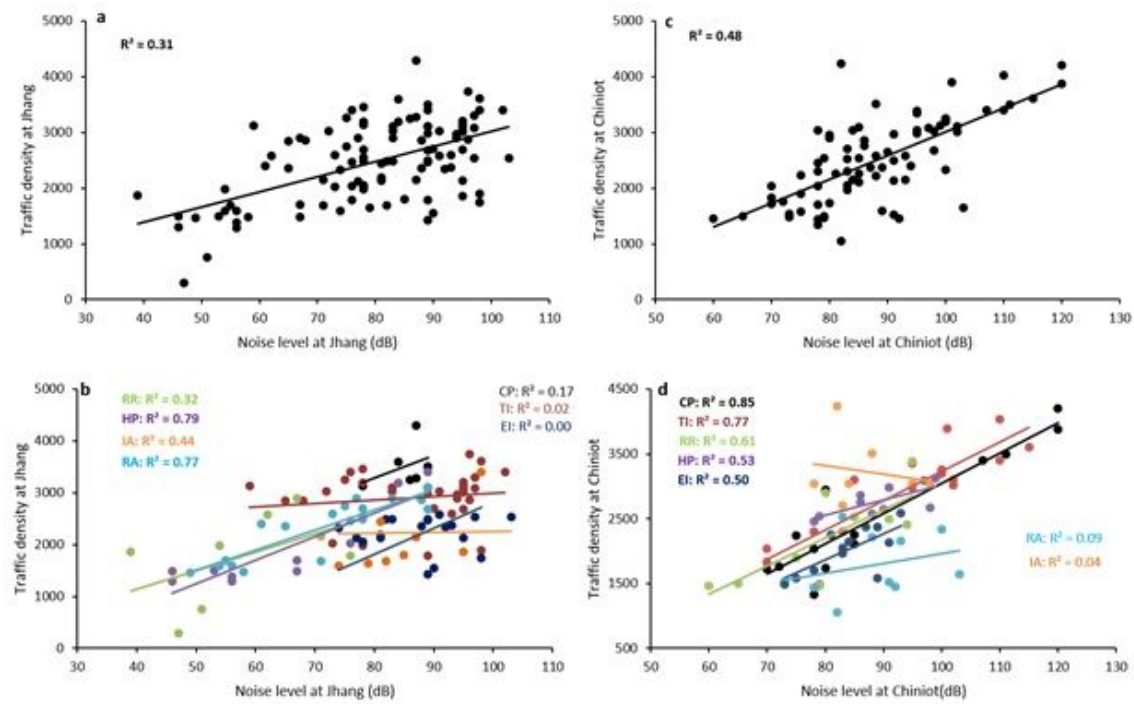

Figure 2

Regression analysis between noise pollution and traffic density in all studied areas of Jhang $(\mathrm{a}, \mathrm{n}=103)$ and Chiniot (c, $\mathrm{n}=78)$, while spatial variability in noise and traffic density at individual source viz. CP: Commercial places ( $n=7$ vs. 13); TI: Traffic intersections ( $n=34$ vs. 17); RR: Religious and recreational places ( $n=9$ vs. 9); HP: Hospitals ( $n=10$ vs. 10); RA: Residential areas ( $n=18$ vs. 10); IA: Industrial areas ( $n=8$ vs. 7$)$; El: Educational institutes ( $n=18$ vs. 12) of Jhang (b) and Chiniot (d). 


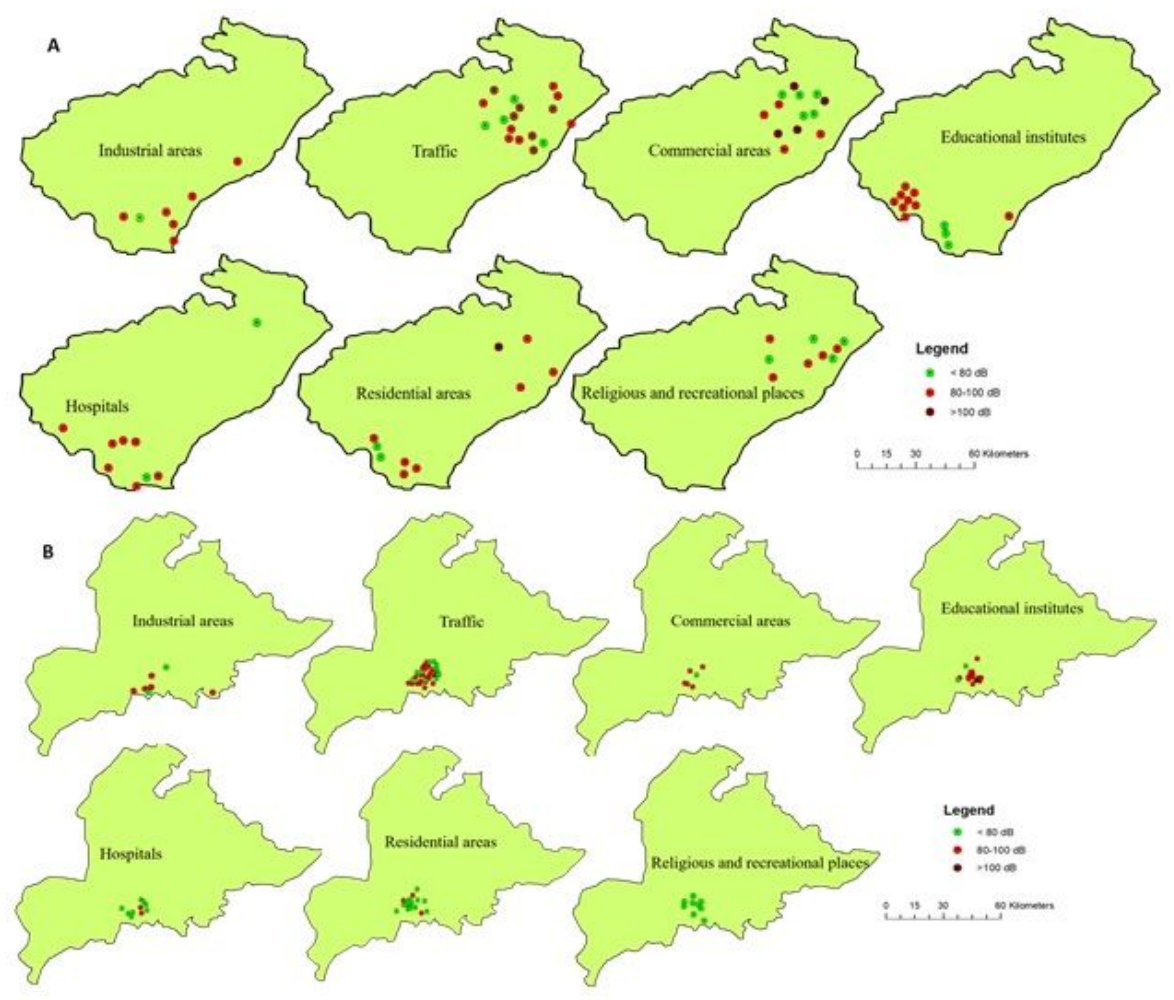

Figure 3

Classification of urban noise pollution of a) Chiniot and b) Jhang famous locations.

\section{Supplementary Files}

This is a list of supplementary files associated with this preprint. Click to download.

- SupplementarymaterialManuscriptJCNoise.docx 